\title{
EFFECT OF DAMPERS ON SEISMIC DEMAND OF SHORT PERIOD STRUCTURES IN DEEP COHESIONLESS SITES
}

\author{
N.S. Armouti \\ Associate Professor of Civil Engineering \\ University of Jordan, Amman 11942, Jordan \\ (Corresponding author: E-mail: armouti@ju.edu.jo)
}

Received: 18 October 2010; Revised: 26 December 2010; Accepted: 3 January 2011

\begin{abstract}
Seismic behavior of short period structures with dampers founded on deep cohesionless soil is investigated. A Single bay frame with diagonal damper that represents short period structures is evaluated in response to the excitation of a set of earthquake records. The frame system is modeled as a Generalized Single Degree of Freedom System, and is subjected to five earthquake records representative of deep cohesionless site conditions. The relationship between the force modification factor and the global ductility demand for short period structures founded on deep cohesionless soil, in the presence of dampers, tends to approach those of long period ones. Compared with seismic demand under general site conditions, short period structures founded on deep cohesionless soil show less seismic demand and lower sensitivity to earthquake excitations. Similar to seismic demand in general site conditions, and except for period of 0.1 second, short period structures in deep cohesionless sites with dampers having damping ratios higher than $20 \%$ tend to keep the structural response in the elastic range even for high values of force reductions. Seismic code provisions should be revised to account for short period effect under seismic excitation.
\end{abstract}

Keywords: Ductility demand, seismic demand, short period, dampers, deep cohesionless soil

\section{INTRODUCTION}

Earthquake-resistant structures are generally designed with strength much less than their elastic strength demand due to earthquake excitation. According to modern seismic codes, typically welldetailed structures may be designed with strength capacity as low as $12 \%$ of their elastic strength demand (IBC [1]).

This reduction in strength demand is possible due to many factors such as ductility, energy dissipation, and frequency shift. In general, such strength reduction imposes special demand on structures in terms of detailing to achieve specified levels of ductility and energy dissipation which are function of the specified levels of strength reduction. Seismic codes, in general, utilize parameters such as force modification factor, $\mathrm{R}$, and global ductility demand, $\mu_{\mathrm{d}}$, to implicitly account for strength reductions. Force modification factor is defined as the ratio of elastic strength demand to actual yield force of the structure, whereas, global ductility demand is defined as the maximum inelastic displacement under seismic excitation to the actual yield displacement of the structure.

However, the codes do not explicitly address the damping of structures which is an indication of the energy dissipation capacity of the structure. Furthermore, codes do not distinguish between short period and long period structures in their treatment of strength and ductility requirements for design of earthquake-resistant structures. 
Many research results on seismic demand indicate that even though ductility demand is feasible for long period structures (tall buildings), they impose high levels of ductility for short period structures (low rise buildings and structures) which may not be achievable (Nassar and Krawinkler [2]). Furthermore, research results also indicate that ductility demand is very sensitive to strength reduction for short period structures (Armouti [3]).

Consequently, short period structures should rely on factors other than ductility to achieve strength reduction such as energy dissipation. Therefore, this study focuses on examining the effect of explicit damping on ductility demand on one hand, and on the feasibility of dampers as an alternative to ductility requirements for short period structures on the other.

Dampers are widely used in structures to alleviate the harmful effect of earthquakes on structures. Dampers are known to be used in new buildings (Nagarajaiah and Narasimhan [4]), in bridges (Madhekar and Jangid [5]), and in retrofit of existing structures (Malhotra et al. [6]), (Potty and Nambissan [7]). Dampers have proven to be effective systems for reducing earthquake forces in structures (Chandra et al. [8]), (Raju et al. [9]), (Takewaki et al. [10]). Performance of dampers near collapse during large seismic events has proven feasible by analytical and experimental investigation (Miyamoto et al. [11]).

The behavior of short period structures with dampers under the excitation of earthquakes representative of dominant site conditions, namely, rock, deep cohesionless soil, and soft areas is investigated (Armouti [12]). The investigation has shown that dampers reduce the high ductility demand of short period structures. In order to explore the deviation of the behavior of short period structures founded on specific site conditions from those founded on the general site conditions presented by (Armouti [12]), this study considers the behavior of short period structures founded on deep cohesionless soil such as sand areas.

In order to examine the effect of dampers on the behavior of short period structures founded on deep cohesionless soil under seismic excitation, a typical one bay frame with a diagonal viscous damper is considered for this study to examine the effect of viscous dampers on the $\mathrm{R}-\mu_{\mathrm{d}}$ relationship. A frame with a damper having a coefficient of damping, C, is subjected to a horizontal component of ground motion, $\ddot{u}_{g}$, as shown in Figure 1 . In order to get a better understanding of the effect of ductility and energy dissipation as outlined above; and to be consistent with previous studies on this subject, the frame is modeled as a generalized single degree of freedom, SDOF, system, and subjected to five earthquake records generated to be representative of earthquakes in deep cohesionless sites. Consequently, the force reduction factor, $\mathrm{R}$, and the global ductility demand, $\mu_{\mathrm{d}}$, are evaluated and compared with previous studies to examine the effect of damping on the ductility demand as an indicator of the behavior of short period structures founded on deep cohesionless soil.

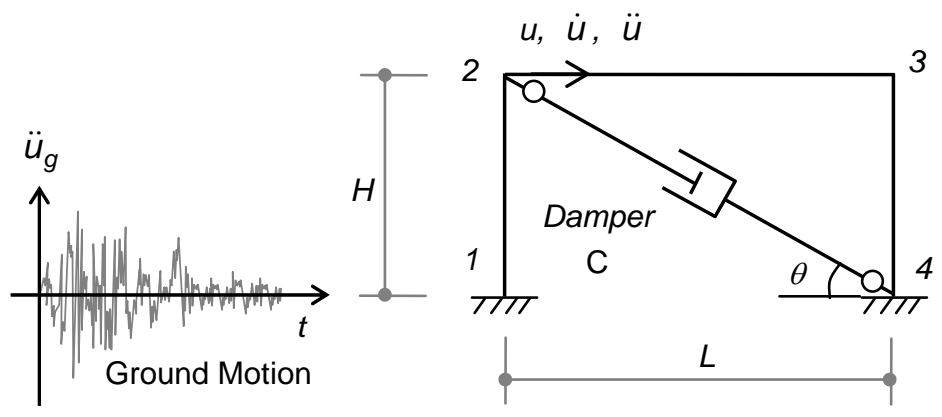

Figure 1. Frame Layout 
To achieve these objectives, a parametric study using inelastic dynamic analysis is performed by varying the period and the intensity of earthquake excitation. The parameter variation includes five periods, five levels of relative yielding of the hysteresis model, and three damping ratios for each of the five earthquake records. This parameter variation results in 375 pairs of $\mathrm{R}$ and $\mu_{\mathrm{d}}$ values as a result of 125 runs of elastic dynamic analysis and 375 runs of inelastic dynamic analysis which are grouped and evaluated.

For completeness of presentation, a description of the structure, the earthquake records used, and the inelastic dynamic analysis procedures including the hysteretic model of the frame are presented.

\section{STRUCTURAL MODEL}

As mentioned previously, the structural model is selected as a frame having four nodes 1 through 4 as shown in Figure 1. The frame consists of one bay frame fixed at both supports which is considered typical of low rise steel buildings, hungers, and storage facilities. The frame is provided with explicit diagonal viscous damper with coefficient of damping, C, between nodes 2 and 4 . The frame may be modeled as a Generalized Single Degree of Freedom, GSDOF, system by assuming the total mass to be lumped at one node, node 2, as shown in Figure 2. The generalized degree of freedom in this case is the mass displacement in the direction of, $\mathrm{u}$, at node 2 . The generalized resistance of the frame without the damper is obtained due to an induced displacement of the mass in direction, $\mathrm{u}$, as a generalized spring force, $\mathrm{F}_{\mathrm{S}}{ }^{*}$, whereas the component of the reactive force of the damper in the direction of displacement, $\mathrm{u}$, is obtained due to induced velocity in the direction of, $\dot{u}$, as the generalized damping force, $\mathrm{F}_{\mathrm{D}}{ }^{*}$.

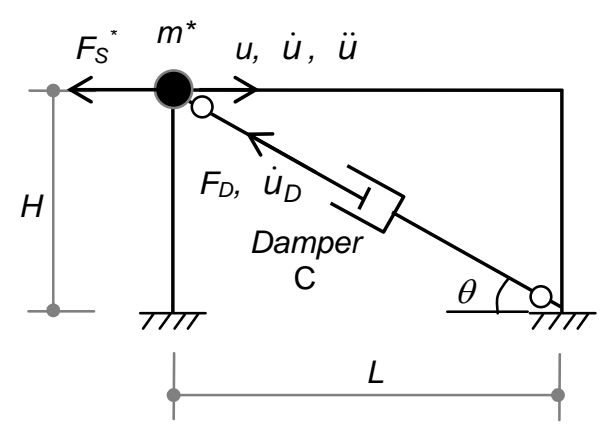

Figure 2. Lumped Mass as GSDOF

In case of elastic analysis, the generalized stiffness, $\mathrm{k}^{*}$, is simply evaluated by subjecting the frame to a unit displacement in direction of, $u$, which can be easily obtained by any structural analysis software. The generalized coefficient of damping, $\mathrm{C}^{*}$, can be obtained as function of the damper coefficient of damping, $\mathrm{C}$, with reference to Figure 3 as follows:

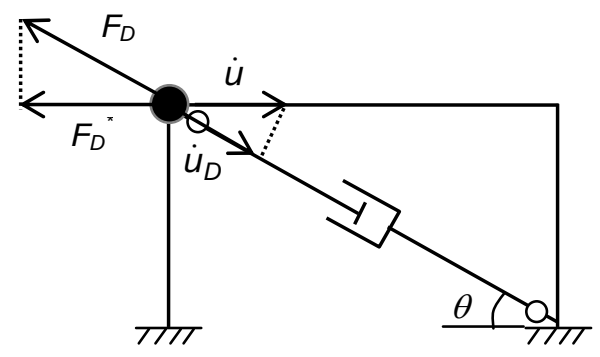

Figure 3. Generalized Damping due to Velocity, $\dot{u}$ 
Since damper velocity is

$$
\dot{u}_{D}=\dot{u} \cos \theta
$$

The force in the damper is given as $\quad F_{D}=C \cdot \dot{u}_{D}=C \cdot \cos \theta \dot{u}$

The generalized force of the damper in the direction of, $\mathrm{u}$, becomes:

$F_{D}{ }^{*}=F_{D} \cos \theta=C \cdot \cos ^{2} \theta \dot{u}=C^{*} \dot{u}$

Therefore, the generalized damping becomes: $\quad C^{*}=C \cdot \cos ^{2} \theta$

The frame system, therefore, can be represented by a system with a generalized single dynamic degree of freedom consists of a lumped mass subjected to a generalized forces and displacements as shown in Figure 4. The equation of motion in this case takes the form

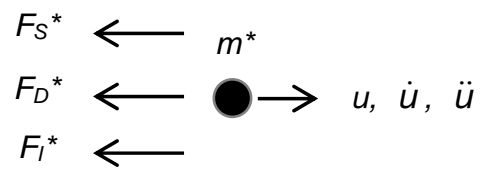

Figure 4. Generalized SDOF

$F_{I}^{*}+{F_{D}}^{*}+{F_{S}}^{*}=-m^{*} \ddot{u}_{g}$

In case of elastic analysis, the equation becomes

$$
\begin{aligned}
& m^{*} \ddot{u}+C^{*} \dot{u}+k^{*} u=-m^{*} \ddot{u}_{g} \\
& \ddot{u}+2 \zeta \omega \dot{u}+\omega^{2} \quad u=-\ddot{u}_{g}
\end{aligned}
$$

where

$u$ = generalized displacement.

$\dot{u}=$ generalized velocity.

$\ddot{u}$ = generalized acceleration.

$\ddot{u}_{g}=$ ground acceleration (earthquake).

$m^{*}=$ generalized mass.

$F_{I}{ }^{*}=$ generalized inertial force.

$C^{*}=$ generalized coefficient of damping.

$F_{D}{ }^{*}=$ generalized damping force.

$k^{*}=$ generalized stiffness.

$F_{S}{ }^{*}=$ generalized spring force.

$\omega=$ frequency of the generalized system.

$\zeta=$ damping ratio of the generalized system.

Since the parametric study uses predefined values of period and damping ratios, the exact values of these parameters, in this study, become immaterial. Therefore, the values of the mass, stiffness, damping, and level of ground motion are adjusted to produce the intended parameter values of the study.

Consequently, the force reduction factor, $\mathrm{R}$, is defined as the ratio of the elastic strength demand of the frame, $F_{e}$, to the actual yield strength, $F_{y}$, whereas global ductility demand, $\mu_{d}$, is defined as the ratio of the maximum displacement that is reached during the excitation history, $\mathrm{u}_{\max }$, to the actual yield displacement of the frame, $\mathrm{u}_{\mathrm{y}}$. These ratios are given in mathematical form as follows 
$R=\frac{F_{e}}{F_{y}}, \quad \mu_{d}=\frac{u_{\max }}{u_{y}}$

\section{RECORDS OF EARTHQUAKES}

In view of earthquake characteristics, earthquake records are selected to be representative of the deep cohesionless soil conditions found in reality. In order to be comparative, three synthetic records that are used in this analysis were adopted from previous studies (Armouti [3]), (Armouti [12]). Additional two records are generated with the same power spectral density curve for deep cohesionless sites. The records are based on the PSD distribution for soft sties given in Figure 5.

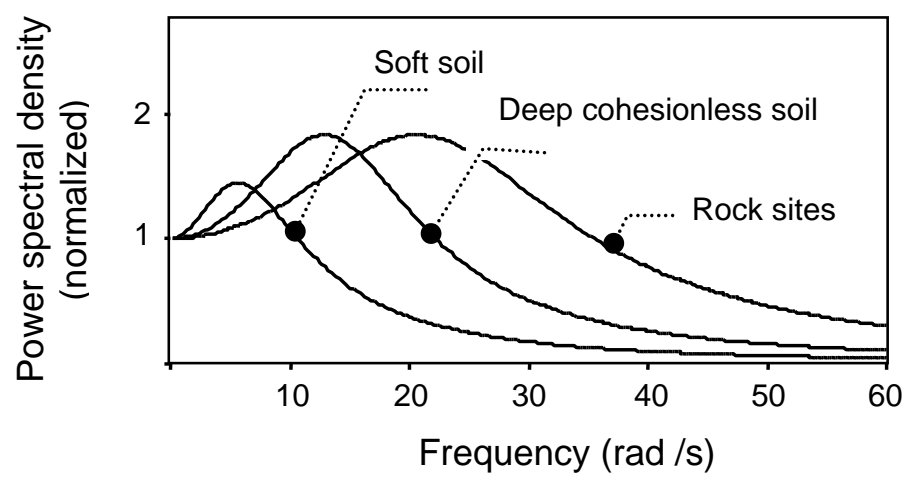

Figure 5. Distribution of Power Spectral Density of Earthquakes According to their Site Conditions

Using this PSD distribution, five synthetic records are generated. If the letter (D) indicates deep cohesionless site for future reference, these records are designated as D1.nsa, D2.nsa, D3.nsa, D4.nsa, and D5.nsa. Sample of these records, D1.nsa, with its associated Fourier Amplitude Spectrum are shown in Figure 6.

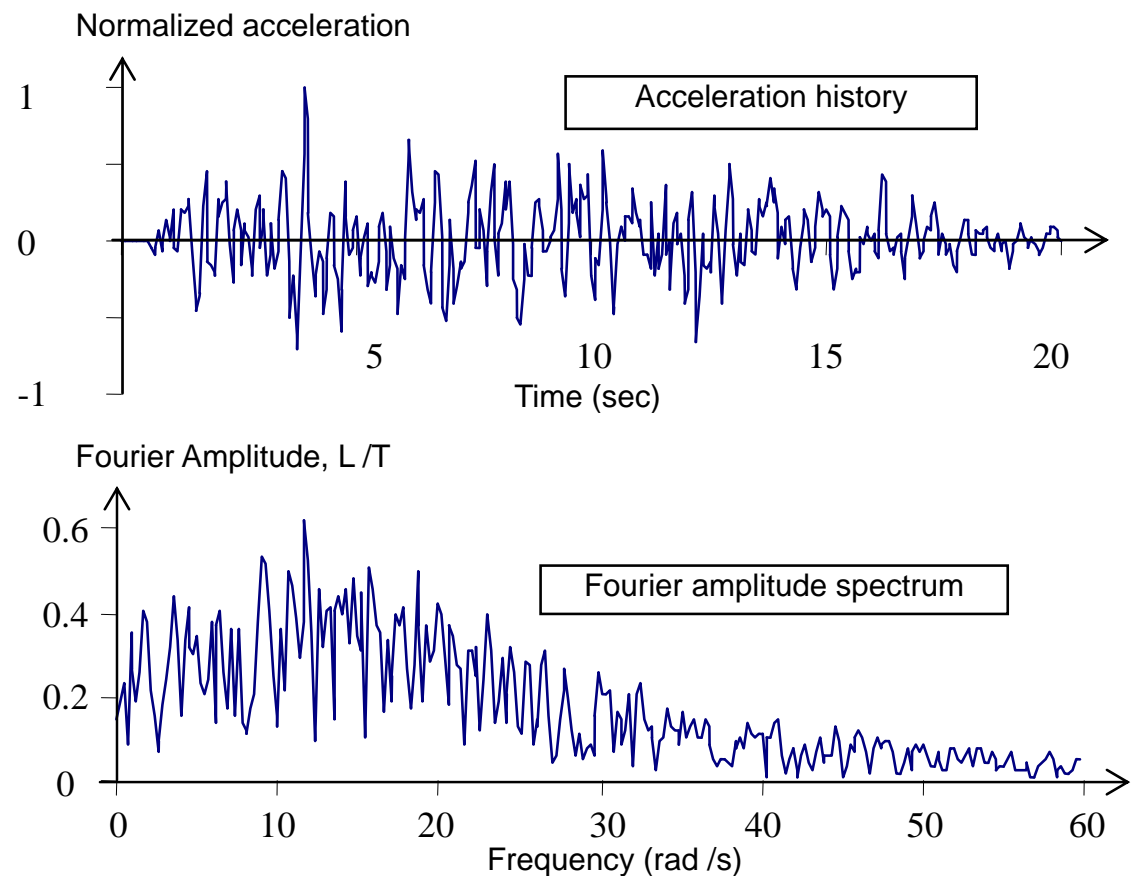

Figure 6. Properties of Synthetic Record D1.nsa 


\section{INELASTIC DYNAMIC ANALYSIS}

The purpose of this study is to examine the effect of viscous dampers on the relationship between $\mathrm{R}$ and $\mu_{\mathrm{d}}$ for short period structures founded on deep cohesionless soil. Since the relationship between $\mathrm{R}$ and $\mu_{\mathrm{d}}$ can only be evaluated in a statistical sense due to the extreme randomness and uncertainty of earthquake characteristics, inelastic dynamic analysis (Clough and Penzien [13]) is needed to generate a data base for this purpose. In addition to the selected five earthquake records, the parameter variation includes five periods, five ductility ratios, and three damping ratio resulting in $5 \times 5 \times 5 \times 3=375$ data points.

The inelastic dynamic analysis can be performed using SAP2000 software (CSI [14]) under Time History Function. The GSDOF frame may be modeled in SAP2000 as direct elasto-plastic link, whereas the damper is modeled as damper link. The parameters of the link and the damper are selected in view of the intended parameter variation values in conjunction with the equation of motion which is given before as

$m^{*} \ddot{u}+C^{*} \dot{u}+k^{*} u=-m^{*} \ddot{u}_{g}$

In case of inelastic dynamic analysis, the stiffness will not be constant, and hence the frame resistance is taken as a reactive generalized restoring force, $F_{S}{ }^{*}$, hence the equation of motion takes its final form as

$m^{*} \ddot{u}+C^{*} \dot{u}+F_{S}^{*}=-m^{*} \ddot{u}_{g}$

where

$u$ = generalized displacement of the mass in the direction of the single degree of freedom.

$\dot{u}=$ generalized mass velocity.

$\ddot{u}$ = generalized mass acceleration.

$\ddot{u}_{g}=$ horizontal ground acceleration.

$m^{*}=$ generalized total mass.

$C^{*}$ = generalized coefficient of viscous damping.

$F_{S}{ }^{*}=$ generalized restoring force (hysteresis model).

The structural response is represented by a bilinear hysteresis model with post yielding stiffness equals to $10 \%$ of its initial stiffness as shown in Figure 7. The properties of the hysteresis model are included in SAP2000 through the elasto-plastic link nonlinear properties. A yield force of 10 $\mathrm{kN}$ and yield displacement of $0.01 \mathrm{~m}$ are used for this purpose. Since the model properties are required arbitrarily to obtain predefined periods, the elastic stiffness, $\mathrm{k}_{0}$, of the model is selected as $1000 \mathrm{kN} / \mathrm{m}$, whereas the mass is calibrated for each case to obtain the desired period since the period is given as

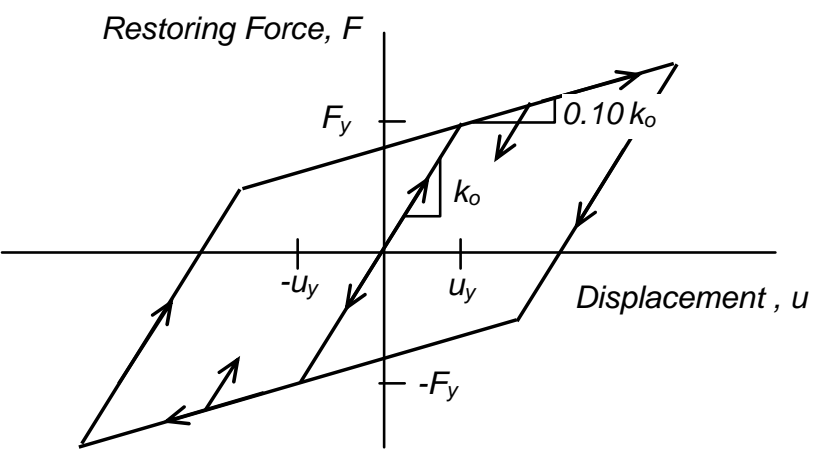

Figure 7. Bilinear Hysteresis Model 
$T=2 \pi \sqrt{\frac{m^{*}}{k^{*}}}$

The generalized damping coefficient is calculated in view of the desired damping ratio and the selected mass and stiffness as follows

The critical damping, $\mathrm{C}_{\mathrm{CR}}^{*}$, is calculated as $\quad C_{C R}^{*}=2 \sqrt{k^{*} m^{*}}$

The damping coefficient, $\mathrm{C}^{*}$, is then calculated as function of damping ratio, $\zeta$ and critical damping, $\mathrm{C}_{\mathrm{CR}}^{*}$, as

$C^{*}=\zeta C^{*}{ }_{C R}$

The five periods of the model are chosen by adjusting the mass to produce the desired period. Since the R- $\mu_{\mathrm{d}}$ relationship is targeted in this study for short period structures, the five periods used in this study are $0.1,0.2,0.3$, and 0.4 seconds. A fifth period of 0.5 seconds is also included in the study as it marks the border line between short and long period values of structures under typical earthquake excitation.

In order to obtain various levels of $\mathrm{R}$ values, the yield level of the frame is kept constant while changing the intensity of the earthquakes, i.e. the peak ground acceleration of the earthquakes. Accordingly, the parameter variation is generated by taking a different level of peak ground acceleration for each period and each earthquake record. The elastic strength demand, i.e. the maximum elastic force, $\mathrm{F}_{\mathrm{e}}$, and the maximum elastic displacement, $\mathrm{u}_{\mathrm{e}}$, are then obtained using elastic dynamic analysis, i.e. Time History Analysis with infinite yielding. The damping ratio is taken $5 \%$ as customary used. For each value of, $\mathrm{F}_{\mathrm{e}}$, an R-value is calculated as follows:

$R=\frac{F_{e}}{F_{y}}$

For each value of R obtained above and for each level of damping of the damper, inelastic dynamic analysis, i.e. Time History Analysis with yielding force, at $10 \mathrm{kN}$, is performed to evaluate the maximum displacement demand during the time of excitation, $\mathrm{u}_{\max }$. Knowing $\mathrm{u}_{\max }$, $\mathrm{u}_{\mathrm{y}}$, the quantities $\mu_{\mathrm{d}}$ is calculated as follows

$\mu_{d}=\frac{u_{\max }}{u_{y}}$

A total number of 375 pairs of $\mathrm{R}$ and $\mu_{\mathrm{d}}$ from the above procedures are obtained. Samples of such results are shown in Figure 8 for 20\% damping ratio and in Figure 9 for $40 \%$ damping ratio. It can be noticed that the data points still exhibit the level of randomness associated with such analysis. 


\section{NASSAR AND KRAWINKLER MODEL}

Based on extensive study resulted in large data base of seismic demand characteristics using fifteen actual earthquake records, Nassar and Krawinkler, N\&K, (Nassar and Krawinkler [2]) have proposed the following expression for a relationship between $\mathrm{R}$ and $\mu_{\mathrm{d}}$ factors as follows

$R=\left[C \cdot\left(\mu_{d}-1\right)+1\right]^{1 / C}$

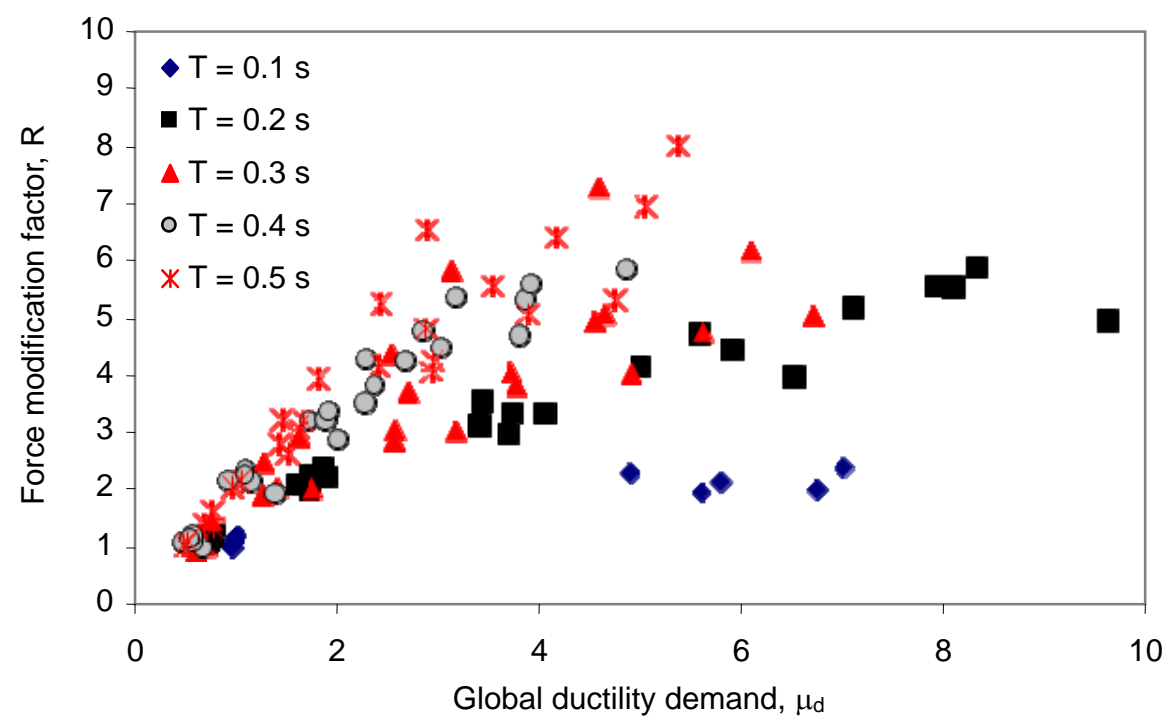

Figure 8. Relationship between Force Modification Factor and Global Ductility Demand at Damping Ratio of 20\%

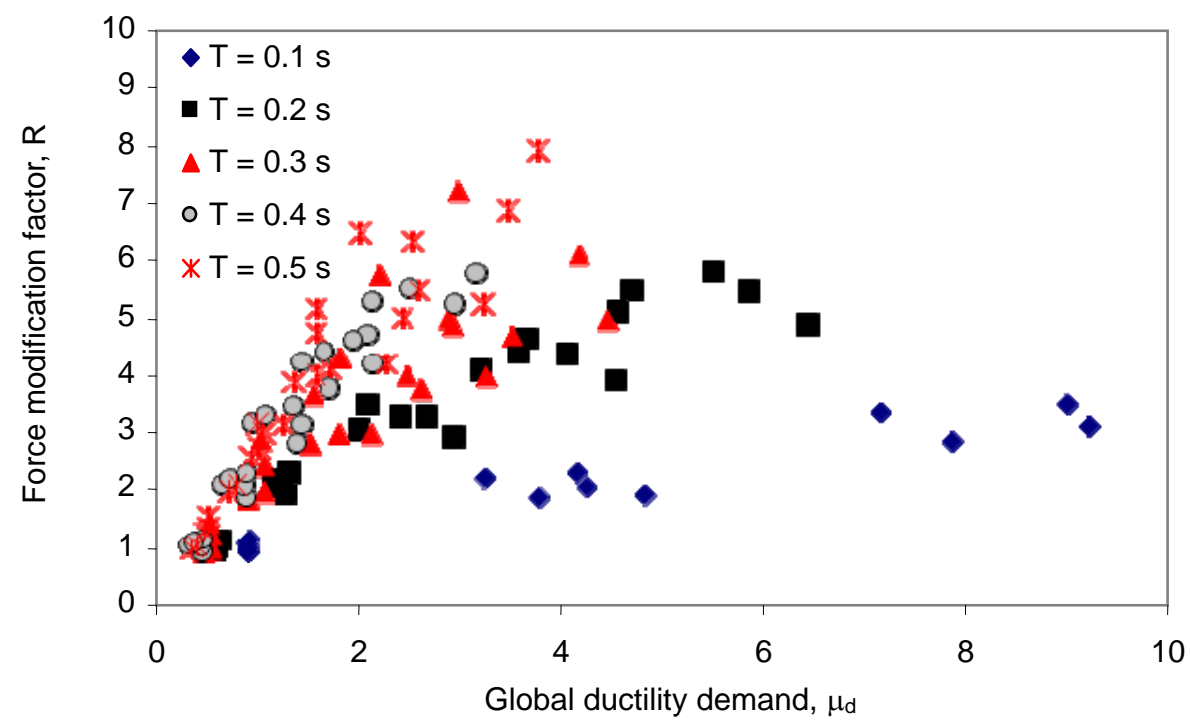

Figure 9. Relationship between Force Modification Factor and

Global Ductility Demand at Damping Ratio of $40 \%$

where $\mathrm{C}$ is given as

$C(T)=\frac{T^{a}}{1+T^{a}}+\frac{b}{T}$ 
For a bilinear model with $10 \%$ post yielding stiffness and typical damping ratio of 5\%, N\&K have used nonlinear regression analysis to produce values of $(a=0.8)$ and $(b=0.29)$. Using these values, a plot of the parameter $C$ versus period $T$ is shown in Figure 10. This figure will be used in this study as the reference relationship between $\mathrm{R}$ and $\mu_{\mathrm{d}}$ for a bilinear hysterisis model under the excitation of earthquake records. It is worthwhile to mention that when the value of the parameter $\mathrm{C}=1$, the $\mathrm{R}-\mu_{d}$ relationship tends to the well known equal displacement criteria $\left(R=\mu_{d}\right)$; and when the value of the parameter $\mathrm{C}=2$, the $\mathrm{R}-\mu_{d}$ relationship tends to the well known equal energy criteria $(R=\sqrt{2 \mu-1})$.

Parameter C

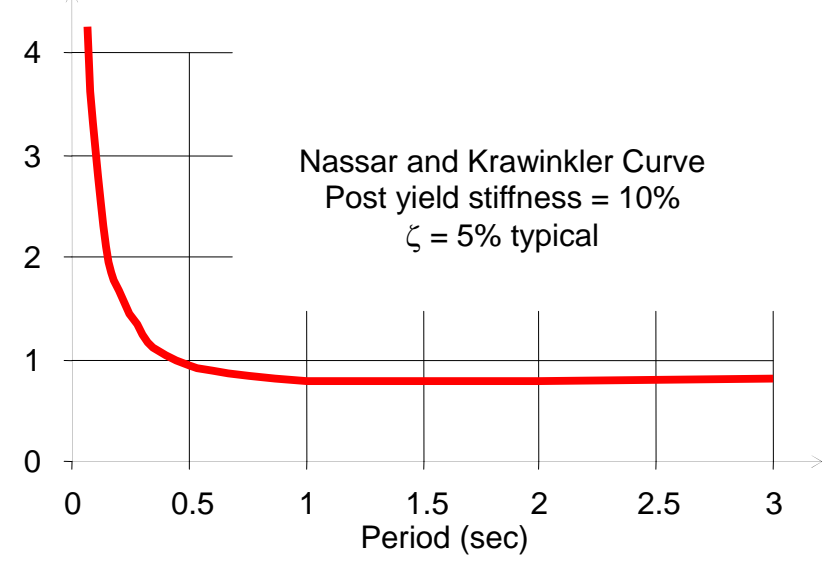

Figure 10. Relationship between Parameter C and Period

(Nassar and Krawinkler [2])

It is worthwhile also to point out that, in the statistical sense, the C-T relationship shown in Figure 10 seems to become steady in the long period region $(\mathrm{T}>0.5 \mathrm{sec})$. For long period regions, where parameter $\mathrm{C}$ is low $(\mathrm{C}<1)$, ductility demand is usually low and steady, whereas, for short period regions where parameter $C$ is high $(C>>1)$, the seismic demand becomes sensitive and high. This type of behavior is known to be a characteristic behavior of structures in response to earthquake excitation. It should also be pointed out that when the value of $C$ is greater than one, the ductility demand becomes more than the force reduction values, and when the value of $\mathrm{C}$ is smaller than one, the ductility demand becomes less than the force reduction values.

\section{ARMOUTI REFERENCE RESULTS FOR GENERAL SITE CONDITIONS}

Response of short period structures with dampers under general site conditions was investigated by Armouti (Armouti [12]). His study considered nine earthquakes representative of the three dominant site conditions, namely, rock conditions, deep cohesionless conditions, and soft soil conditions where three earthquakes of each type where included in the analysis. A comparison with N\&K model was presented as shown in Figure 11 where the study showed that using dampers have smoothen seismic demand in presence of dampers for short period.

Table 1 shows values of the parameter $\mathrm{C}$ obtained by Armouti study which are also plotted in Figure 11 for reference comparison with this study which includes the effect of dampers on short period structures founded on deep cohesionless sites. 
Table 1 Nonlinear regression results for parameter $\mathrm{C}$ under general site conditions (Armouti [12])

\begin{tabular}{|c|c|c|c|c|}
\hline \multirow{2}{*}{$\begin{array}{c}\text { Period } \\
\text { (second) }\end{array}$} & \multicolumn{4}{|c|}{ Damping ratio } \\
\cline { 2 - 5 } & $20 \%$ & $40 \%$ & $60 \%$ & $80 \%$ \\
\hline 0.1 & 2.75 & 2.35 & 2.09 & 1.88 \\
\hline 0.2 & 1.42 & 0.89 & 0.56 & 0.31 \\
\hline 0.3 & 1.08 & 0.63 & 0.35 & 0.18 \\
\hline 0.4 & 0.84 & 0.31 & $* * *$ & $* * *$ \\
\hline 0.5 & 1.03 & 0.67 & 0.39 & 0.17 \\
\hline
\end{tabular}

Parameter C

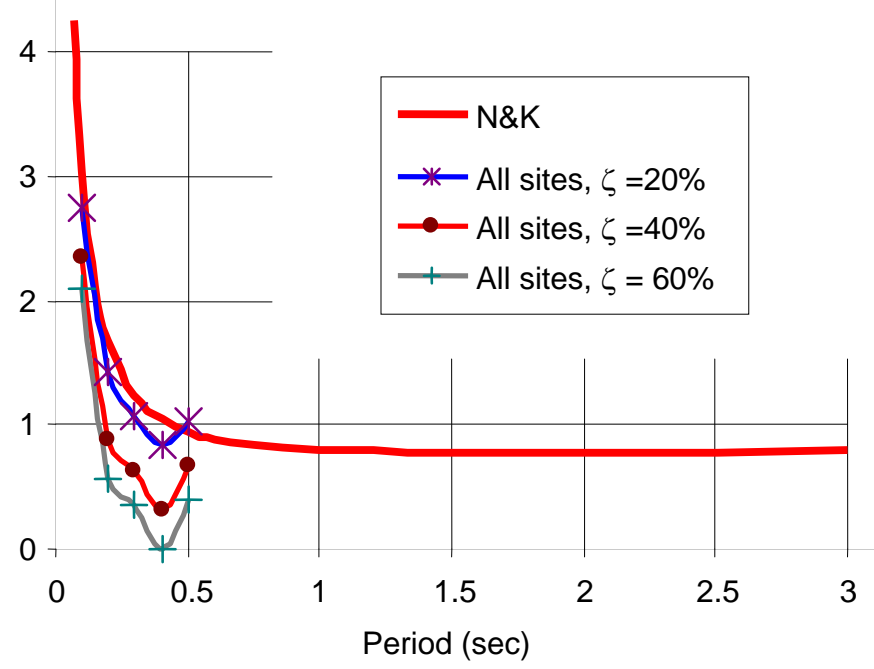

Figure 11. Values of Parameter C for Different Periods from Reference Models of N\&K [2], and Study of Armouti [12]

\section{ANALYSIS OF NUMERICAL RESULTS}

Evaluation of the numerical results obtained as outlined previously is accomplished through comparison with N\&K model and (Armouti [12]) results which is established by finding the parameter $\mathrm{C}$ at the selected periods of the system under the excitation of the selected earthquake records at each damping ratio. The resulting values of the parameter $C$ will then be compared with C-T plot results from N\&K model and Armouti results.

Figure 12 shows one sample of nonlinear regression curve used to find the parameter $\mathrm{C}$ for a period of 0.1 second at damping ratio of $20 \%$, from which a value of $\mathrm{C}=2.751$ is obtained. Similar nonlinear regression analysis is conducted to produce the rest of the C-values for the selected periods as given in Table 2. 
Force modification factor,

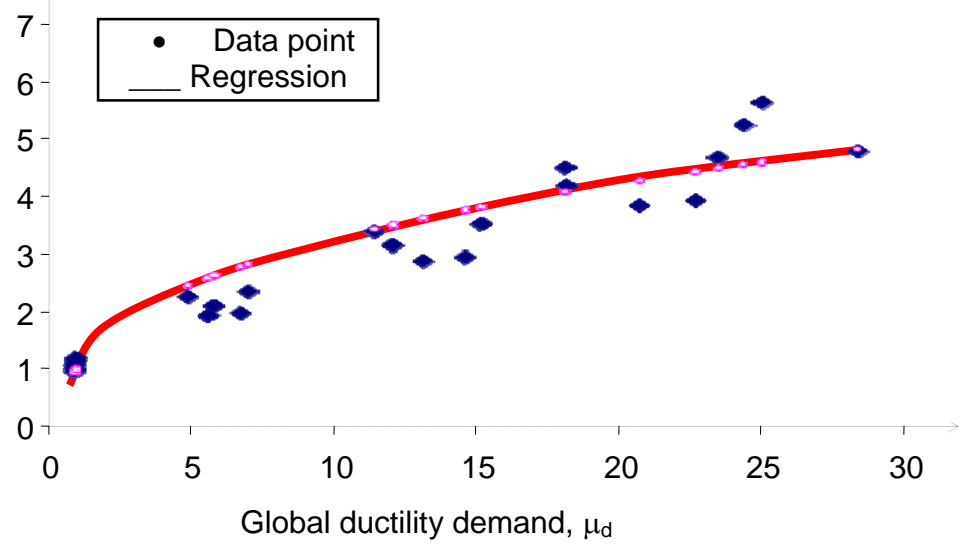

Figure 12. Sample Nonlinear Regression Curve for C Value at Period of 0.1 sec and Damping Ratio of 20\%

Table 2 Nonlinear Regression Results for Parameter C under Deep Cohesionless Site Conditions

\begin{tabular}{|c|c|c|c|}
\hline \multirow{2}{*}{$\begin{array}{c}\text { Period } \\
\text { (second) }\end{array}$} & \multicolumn{3}{|c|}{ Damping ratio } \\
\cline { 2 - 4 } & $20 \%$ & $40 \%$ & $60 \%$ \\
\hline 0.1 & 2.75 & 2.31 & 2.04 \\
\hline 0.2 & 1.43 & 0.99 & 0.71 \\
\hline 0.3 & 1.00 & 0.54 & 0.19 \\
\hline 0.4 & 0.61 & 0.10 & $* * *$ \\
\hline 0.5 & 0.62 & 0.22 & $* * *$ \\
\hline
\end{tabular}

Parameter C

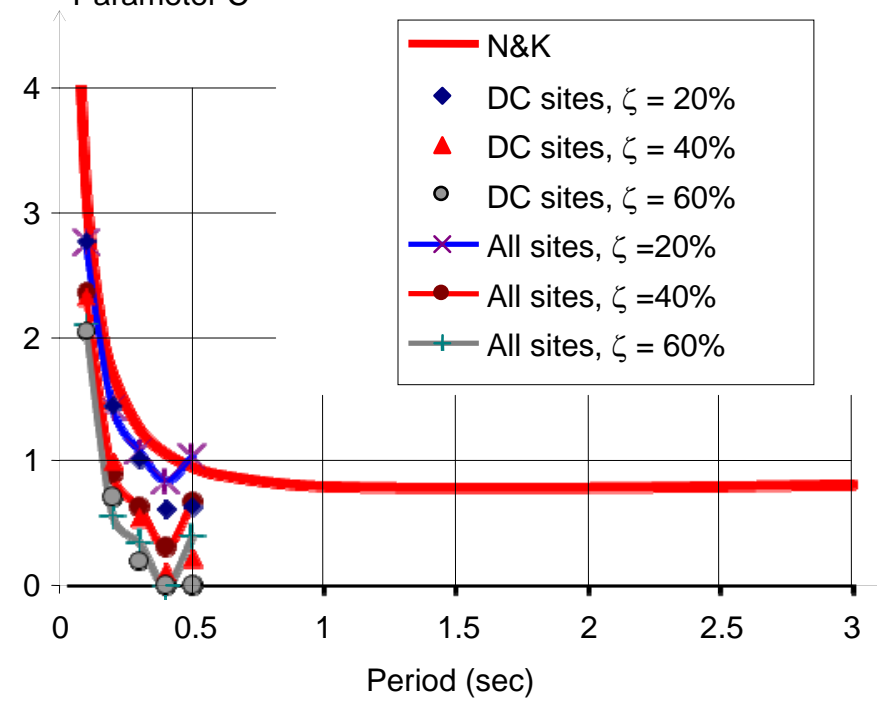

Figure 13. Values of Parameter C for Different Periods from this Study Against Reference Models of N\&K [2], and Armouti [12] 


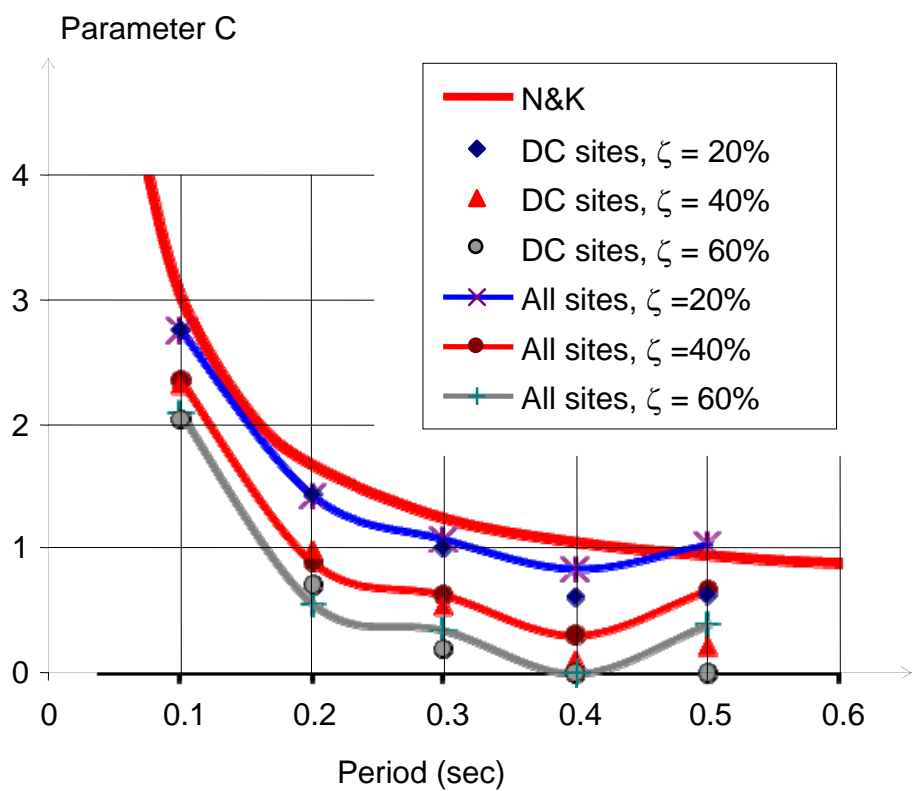

Figure 14. Values of Parameter C for Different Periods from this Study Against Reference Model of N\&K [2], and Armouti [12]

Figure 13 and Figure 14 show a comparison between the obtained C-values from this study and the references N\&K model and (Armouti [12]) results. It can be observed that the results from this study almost coincide with the results of All-site conditions for periods 0.1 and 0.2 second, whereas for periods $0.3,0.4$, and 0.5 second, these results lie below those of All-site conditions curves given in N\&K and Armouti studies. It can therefore be noted that the behavior of short period structures founded on deep cohesionless soil tends to be less demanding than those in the general site conditions.

It can also be noted that the C-values for the period of 0.1 second remain above the value of 2 which means that, for this period even with high values of damping, the ductility demand remains much higher than force reduction. However, high damping brings the level of demand closer to a value of 2 which is the equal energy criterion. Furthermore, the figure indicates that the behavior of short period structures founded on deep cohesionless area requires less seismic demand than those founded on general site conditions.

Since the C-values for period of 0.1 second remains in the high range values regardless of the damping values, it can be concluded that dampers have little effect on the behavior of structures with period of 0.1 second, therefore, structures of period of 0.1 second needs measures to elongate the period rather than increasing damping. Seismic isolation, for example, offers an ideal solution in this case since it usually shifts the period to the long period range resulting in large reduction in seismic forces.

Referring to Figure 8 and Figure 9, the scatter of data can be observed which is reflected by the extreme randomness of earthquakes and their random effect on the response of structures. Careful examination of these two figures shows that the data points of Figure 9 (40\% damping) seem to shift to the left of the data points of Figure 8 (20\% damping) indicating less ductility demand with increased damping. Furthermore, it should be noticed that many responses of the structure remain elastic at reduced force values which are marked by the values of $(\mathrm{R}>1)$; and the values of $\left(\mu_{\mathrm{d}}<\right.$ 1). This general trend is also observed in the case of response of short period structures under general site conditions in previous research (Armouti [12]). 
Comparison between Figure 8 and Figure 9 indicates also that the points that remain elastic at reduced force are much more for the case of $40 \%$ damping than the case of $20 \%$ damping. It can be noticed also that the structure with $40 \%$ damping remains elastic at higher values of $\mathrm{R}$ ( $\mathrm{R}$ goes up to 3 ) than the structure with $20 \%$ (R goes up to 2). In other words, the reduction in elastic strength demand is simply shared between the system ductility and the damper.

\section{CONCLUSIONS}

Response of structures to earthquake records are known to impose high ductility demand on short period structures much higher than those of long period structures. Such high demand for short period structures may not even be feasible to achieve. Seismic codes, in general, overlook this issue and do not distinguish between long and short periods for this matter.

Armouti (Armouti [12]) has evaluated the effect of explicit dampers as a mean of alleviating the high ductility demand for short period structures through parametric study using one bay frame with diagonal damper under the excitation of nine earthquakes representative of dominant site conditions. His work examined this issue through the relationship between the force modification factor and the global ductility demand under seismic excitation as defined by most modern seismic codes (IBC [1]). This relationship constitutes the basic relationship for defining seismic design forces and the associated required ductility capacities.

In view of the extreme randomness of earthquake characteristics and the reflection of this randomness on the response of structures, and in order to explore the deviation of the behavior of short period structures founded on specific site conditions from those founded on the general site conditions, this study focuses on the response of structures founded on deep cohesionless sites. The obtained results in this study indicate, in statistical sense, that the response of short period structures founded on deep cohesionless soil to earthquakes after yielding is in fact close but less sensitive and less demanding than the case of response to earthquakes under general site conditions. Except of periods of 0.1 second, dampers with higher critical damping than $20 \%$ seem to bring the behavior of short period structures to levels of the behavior of long period ones. Even more, they show that higher damping improves the behavior of short period structures to levels that are feasibly achievable in practice. It has also been found that the higher the damping presence in the structure, the higher will be the presence of elastic behavior of the structure at even higher values of force reduction.

This study also indicates that dampers have little effect on the behavior of structures with period of 0.1 second, therefore, structures of period of 0.1 second need measures to elongate the period rather than increasing damping, for example, seismic isolation systems.

It can be concluded that response of short period structures founded on deep cohesionless sites is close, but less demanding than the response of short period structures founded on general site conditions, which emphasizes that structures with short periods founded on deep cohesionless soil still need attention to be carefully designed taking into consideration additional measures other than ductility to include some acceptable levels of safety. Furthermore, as this issue is overlooked in seismic codes, the codes ought to revisit the concept of force reduction and distinguish between long period structures and short period structures. Short period structures may need additional provisions to provide them with enough safety measures. 


\section{REFERENCES}

[1] IBC., "International Building Code”, International Code Council, Washington, DC. 2006

[2] Nassar, A. A. and Krawinkler H., "Seismic Demands for SDOF and MDOF systems”, The John A. Blume Earthquake Engineering Center, Stanford University, California, 1991, Report No. 95.

[3] Armouti, N.S., "Response of Structures to Synthetic Earthquakes", Proceeding of the $9^{\text {th }}$ Arab Structural Engineering Conference, Abu Dhabi, UAE, 2003, Vol. 1, pp. 331-339.

[4] Nagarajaiah, S. and Narasimhan, S., "Seismic Control of Smart Base Isolated Buildings with New Semiactive Variable Damper”, Earthquake Engineering and Structural Dynamics, 2007, Vol. 36, No. 6, pp. 729-749.

[5] Madhekar, S. and Jangid, R., "Variable Dampers for Earthquake Protection of Benchmark Highway Bridges”, Smart Materials and Structures, 2009, Vol. 18, No. 11, pp. 115011, No. 18.

[6] Malhorta, A., Carson, D., Gopal, P., Braimah, A., Giovanni, G. and Pall, R., "Friction Dampers for Seismic Upgrade of St. Vincent Hospital, Ottawa", Proceeding of the 13th World Conference on Earthquake Engineering, Vancouver, B.C., Canada, 2004, Paper No. 1952.

[7] Potty, N. and Nambissan, S., "Seismic Retrofit of Elevated Steel Water Tanks", Proceeding of the International Conference on Construction and Building Technology, Kuala Lumpur, Malaysia, 2008, pp. 99-108.

[8] Chandra, R., Masand, M., Nandi, S., Tripathi, C., Pall, R. and Pall, A., "Friction-dampers for Seismic Control of La Gardenia Towers South City, Gurgaon, India”, Proceeding of the 12th World Conference on Earthquake Engineering, Auckland, New Zealand, 2000, Paper 2008.

[9] Raju, K., Prasad, A., Lakshmanan, N., Muthumani, K., Jagadish, D. and Amuthasheela, R., “Optimum Distribution of Viscous Fluid Dampers in Structural Systems”, Journal of The Institution of Engineers (India), 2005, Vol. 86, pp. 103-108.

[10] Takewaki, I., Katsura, K. and Ku, N., "Earthquake Input Energy to Two Buildings Connected by Viscous Dampers”, Journal of Structural Engineering, ASCE, 2007, Vol. 133, No, 5, pp. 620-628.

[11] Miyamoto, H.K, Gilani, A.S.J., Wada, A. and Ariyaratana, C., "Limit States and Failure Mechanisms of Viscous Dampers and the Implications for Large Earthquakes”, Earthquake Engineering and Structural Dynamics, 2010, Vol. 39, No. 11, pp. 1279-1297.

[12] Armouti, N.S., "Effect of Dampers on Seismic Demand of Short Period Structures", Jordan Journal of Civil Engineering, 2010, Vol. 4, No. 4, pp. 367-377.

[13] Clough, R.W. and Penzien, J., "Dynamics of Structures”, 2nd Ed., McGraw Hill, New York, 1993.

[14] CSI, "Structural Analysis Program, SAP2000 Nonlinear Version 12”, Computers and Structures, Inc., Berkeley, California, 2008. 